\title{
APPLICATION OF THE MEASURING METHOD FOR THE PARAMETERS OF REPUTATIONAL POTENTIAL ON THE EXAMPLE OF UKRAINIAN SUPERMARKET BRANDS
}

\author{
Andrii Kashpur \\ Postgraduate Student, Kyiv National University of Trade and Economics, Ukraine \\ e-mail: andrii.kashpur@gmail.com,orcid.org/ 0000-0002-5954-9060
}

\section{Summary}

This research examines the approaches to the definition and evaluation of a brand reputational potential. The main characteristics of the brand reputation that influence the evaluation of its potential by stakeholders are analyzed on the basis of the existing RQ and RepTrak research methods. The actual vision of the evaluation tasks of brand reputational potential is outlined. The author formulates the Reputation.Construction method that allows to solve these problems with less resources (including time and money) in comparison with other existing methods. The novelty of the Reputation.Construction method is explained specifically by the fact that it is based on the 8 positional brand reputation profile description matrix that is unified for different stakeholders and brands and it allows to determine the differences in perception of brand reputation for each matrix parameter by different stakeholders. Furthermore, an example of Reputation.Construction application in practice is given and an approach to creating an integrated reputational potential indicator of the brand is proposed. The practical significance of the results of this study is to increase the effectiveness of methods of evaluating the reputational potential by expanding the field of application of different methods depending on the specific situation and tasks for the development of brand reputation.

Keywords: reputation, brand, branding, reputational potential, social research, reputation management.

\section{DOI https://doi.org/10.23856/3934}

\section{Introduction}

The definition and fixation of the current attitude of stakeholders to the brand reputation is one of the urgent tasks of reputation management. British scholar K. Murray considers reputation as a type of public relations that involves obtaining of a certain credit of trust to create public goods by the organization (Murray, 2003: 144). Researchers Paul A. Argenti and Bob Druckenmiller note that reputation is a collective representation that includes the relations of the organization with all stakeholders, which can either improve or deteriorate depending on the activities of the company (Argenti, 2004: 369).

After analyzing the genesis of the concept of reputation and its current role in social and marketing communications, the author of this study provides the following definition: «reputation is the present trust in the future intentions of the entity based on its subjective actions in the past» (Kashpur, 2015: 1). Therefore, reputation is a resource that can be used to legitimize the social or business position of the reputation carrier, the price of its goods or services. According to Joachim Klewes, reputation management allows stakeholders to establish trust in an entity, which is a reputation carrier. This trust ensures willingness to cooperate with a reputation carrier. Thus, a positive reputation provides the long-term competitive benefits to a company or organization (Klewes, 2009: 24). 
Consequently, it is important to create methods for measuring the perception of the entity/brand reputation by different stakeholders, the impact of these stakeholders on each other and to determine the potential of brand reputation in creating/developing trust of stakeholders to their intentions.

\section{The objectives of the measuring methods for brand reputational potential}

When formulating the requirements for methods of measuring reputation, Ukrainian researcher from the Reputation Capital Group company I. Sokolovsky provides the following list (Sokolovskyj, 2017)

- to be comprehensible and transparent;

- to have quantitative/digital value;

- to take into consideration the complexity of the concept of reputation and the influence that not only the communication functions, but also other actions performed by the company have on it;

- to be relevant for different research areas (the perception by different groups of stakeholders, the measurement in the media);

- to demonstrate specific mechanisms and opportunities to influence the reputation for transferring business tasks and action plan into the language;

- to be relevant for temporal analysis;

- to have the ability to be used to set the key performance indicators (KPIs).

The methods such as Reputation Quotient (RQ) developed by Harris Pool Company and RepTrak created by Reputation Institute will be considered as the examples of the application of these principles.

The Reputation Quotient method is about determining how different stakeholders perceive the reputation of companies in various sectors (The Reputation of America's 100 Most Visible Companies, 2016).

The scale consists of six dimensions/categories:

- emotional appeal;

- products \& services;

- vision \& leadership;

- workplace environment;

- social responsibility;

- financial performance.

Each of the dimensions/categories is revealed (detailed) with the help of several attributes. The list of attributes was developed on the basis of a large number of qualitative and quantitative studies conducted in the United States, Europe and Australia within the period from 1998 to 2000 (Fombrun, 2007: 250). The scale was tested in the study of the IT sector in the years that followed. The test has confirmed that the RQ scale accurately reflects two fundamental dimensions/categories such as emotional appeal and five rational components (Carreras, 2013: 357).

This method assigns the equal importance to each item because it assumes that all aspects make the same contribution to the overall reputation level. This particular aspect of the method is considered to be its disadvantage by some researchers. For instance, Angel Alloza and Luis Carlos Martinez emphasize that the equal importance of dimensions/categories in the context of calculating the overall rating does not reflect the uneven impact of dimensions/ categories on reputation, although this particular information is of strategic importance for reputation management (Carreras, 2013: 359). The second disadvantage of this method is that the 
scale confuses the levels of explanations (causes) with the levels of consequences (e.g., emotional appeal) that complicates its interpretation. Moreover, the researcher points to the fact that the importance of the five cognitive elements exceeds only one emotional element (emotional appeal) (Carreras, 2013: 359).

The RepTrak method consists of 21 attributes grouped into 7 dimensions (Sokolovskyj, 2017). The difference between RepTrak and RQ is that RepTrak clearly differentiates between two «levels» of reputation perception, i.e. emotional and rational.

The basis for the indicators of RepTrak global reputation is four core statements on which, according to the developers, the emotional attention of stakeholders is focused regarding the reputation entity:

- I have a good feeling about this company;

- I trust this company;

- I admire and respect this company;

- This company has a good reputation.

At the rational level, the model includes seven dimensions or facets that are decomposed into attributes:

- products \& services;

- leadership;

- performance:

- workplace;

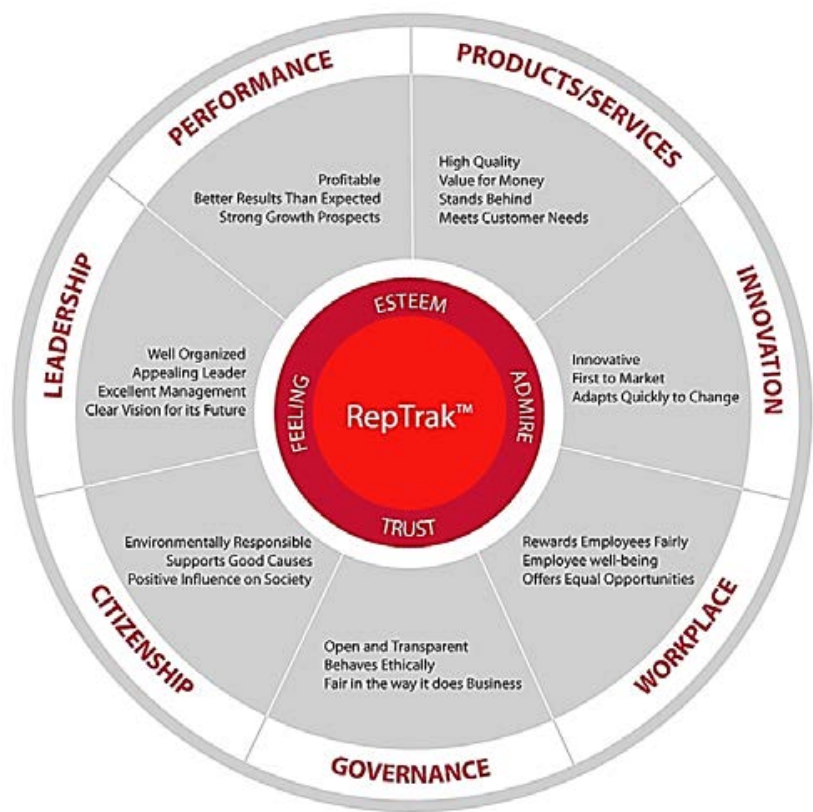

Figure 1. RepTrak reputation management model created by Reputation Institute, Available at: https://www.researchgate.net/figure/RepTrakReputation-Model-Reputation-Institute-2017RepTrak-is-the-standard_fig1_323522768
- citizenship;

- innovations;

- governance.

Thus, the model as a whole looks as follows (Figure 1):

Level 1. Emotional perception (RepTrak Pulse Index).

Level 2. Rational dimensions and attributes that affect the formation of reputation.

Level 3. Supportive behavior, i.e. the willingness to support the entity that is based on its reputation.

According to the developers, the obtained RepTrak Pulse index has showed the corresponding psychometric qualities of convergence, uniformity and differentiation in the construction of behavioral intentions of respondents. In addition, it has confirmed the ability to explain the positive attitude of different stakeholders to companies in different countries. The higher the reputation of the company (RepTrak Pulse index), 
the higher the level of supportive behavior (support) shown by stakeholders in relation to the company. Therefore, the higher the level of supportive behavior (that includes the willingness to buy products/services of the company, willingness to pay a premium price for them, etc.), the higher the financial results of the company where reputation is seen as the result of stakeholders interpreting what is heard and seen on the basis of the communications of the company and its presence in the media.

This method has now spread worldwide and it is applied by many companies and even governments. However, it also has its drawbacks. For instance, researcher Deborah Vidaver-Cohen from the College of Business at University of Florida notes that the RepTrak method provides a small choice of opportunities [10]. First of all, it does not examine enough how positive reputation ratings can eventually turn into company assets.

Deborah Vidaver-Cohen emphasizes that it should be possible to examine which specific reputation ratings of stakeholders generate the financial, intellectual or social capital in the future research methods. The researcher also believes that this method is not universal for different types of business schools, i.e it does not take into account the various business approaches. According to Deborah Vidaver-Cohen, an additional limitation of the method is that it does not include a system of interrelations between RepTrak quality parameters and stakeholder expectations, such as Institutional Forces and Organizational Signaling Strategies. The Institutional Forces research shows that stakeholder expectations of a company performance are reinforced by external forces that include dominant moral values, cultural norms, regulatory requirements and common performance standards of the company in specific sectors or countries. Over time and in different contexts the institutional pressure options can affect stakeholder expectations, as well as the degree of their interest in various aspects of the company benefits (Vidaver-Cohen, 2007: 278).

In addition, the RepTrak method has a high cost of research and a fairly long period of time required for its implementation. Thus, the method can be effectively applied to work with the reputation of the large entities (large companies, markets, countries) with high inertia, but it is ineffective for working with mobile entities in a dynamic space. According to the author, these particular limitations are crucial to the practical application of the method in Ukraine, especially taking into account the transforming tendencies and principles of the communication models and the economy.

\section{The principles and mechanics of the Reputation.Construction method}

According to the above information and own desk research, modeling and practice of applying different methods of measuring the brands reputational potential, the author of this study has formulated the objectives and patterns of the method that should solve the following tasks:

- to measure the attitude of different stakeholders of brand reputation according to the standardized system of parameters for all stakeholder groups;

- to provide an opportunity to compare the attitudes of different stakeholders to the brand reputation and to compare the attitudes of stakeholders to the different brands;

- the ability to calculate an integrated brand reputation indicator;

- to be convenient in usage and optimal in terms of resource costs (time, finances, etc.).

This method is called Reputation.Construction and it is based on 8 attributes of the reputation profile description, developed by the author of «Reputation Matrix» in 2015 (Kashpur, 2015: 10), which are in the coordinate system: temporal (past, present, future) and conceptual (idea, knowledge, matter), where there is a three-dimensional indicator of current 
brand perception by the stakeholder-respondent: reputation/level of trust/willingness to recommend instead of the "knowledge today" central position.

Accordingly, the matrix has the following list of reputational attributes (presented in a linear format): idea/past, idea/present, idea/future, knowledge/past, knowledge/future, matter/ future, matter/present, matter/past with a separate position such as reputation/level of trust/ willingness to recommend.

This approach is significantly simplified compared to the RQ and RepTrak methods discussed above. At the same time, it allows to show the attitude of stakeholders to the brand reputation in the time dynamics regarding three key horizons of perception. As a result, it is possible to conduct surveys that consist of a single list of questions among different stakeholders and to compare them with each other.

The second important principle of the Reputation.Construction method is that the respondents primarily evaluate the importance of the ideal brand parameters and then give ratings to real brands. This allows to identify the differences between «expectations» and «reality» and to count the positive or negative difference for each reputational attribute and then the stakeholder reputational potential indicator of the brand (SRPI), i.e. the compliance of its reputational potential with the expectations of a particular stakeholder group.

The third step is to determine the integrated reputational potential indicator (IRPI) of the brand for all stakeholder groups. The IRPIs are calculated on the basis of the amount sum of the SRPIs, each of which is adjusted by the "stakeholder impact index" that is determined by evaluating the importance of the impact on the brand reputation of themselves and other stakeholders.

The method is implemented as an online survey during which the level of detail of the brand stakeholders is determined and the required/valid number of respondents who are interviewed on a single questionnaire is recruited for each defined stakeholder group.

\section{The example of the Reputation.Construction method application}

The application of the method is considered on the example of the "Reputation of supermarkets in Ukraine" study that was held according to this method in December 2019 - January 2020 in Kiev, Ukraine.

The study was conducted in two stages. At the first stage, the following data was obtained through one-on-one interviews:

- a list of brands that respondents think are most commonly associated with the «supermarket» format, i.e. «Silpo», ATB, NOVUS, «ECO-Market», «Furshet», «Velyka Kyshenia».

- the number and structure of stakeholder audiences:

- consumers (200 respondents) - men and women (50/50) who regularly interact with at least two of the listed brands; the age structure and income of the audience correspond to the demographic model of Kyiv at the time of the survey;

- employees (up to 20 respondents) - the middle management staff (middle managers of central offices and directors/deputies of the stores;

- journalists (up to 20 respondents) - the current employees of socio-political media with a wide range of information interests;

- entrepreneurs and businessmen (up to 20 respondents) - the managers and owners of companies, individual entrepreneurs with a high level of income whose activities are not related to supermarkets;

- civil servants (up to 20 respondents) of the middle and senior rank (from the heads of departments to the deputy ministers) whose activities are not related to the supermarkets.

- The questions to respondents that most accurately correspond to their perception of the 8 attributes of the reputation matrix (Table 2). 
The formulation of questions to respondents in accordance with the attributes of the reputation matrix

\begin{tabular}{|c|c|}
\hline Attribute & Question \\
\hline idea/past & Transparent/public and positive history \\
\hline idea/present & Clear and useful information/advertising \\
\hline idea/future & Clear and positive ideology and development goals \\
\hline knowledge/future & Modern technologies and approaches in the work \\
\hline matter/future & Prompt response to the concerns and their alleviation \\
\hline matter/present & Convenient and clean supermarkets with an appropriate range of goods \\
\hline matter/past & Competent and friendly staff \\
\hline knowledge/past & High-quality and convenient service \\
\hline
\end{tabular}

At the second stage, the respondents from all stakeholder groups were asked to fill out an online questionnaire consisting of five sets of questions (Table 3).

Table 3

\section{Questions to respondents}

\begin{tabular}{|c|c|c|}
\hline Sets of questions & $\begin{array}{l}\text { Number } \\
\text { of the } \\
\text { question }\end{array}$ & Question \\
\hline \multirow{6}{*}{$\begin{array}{l}\text { Introductory set } \\
\text { of questions (self- } \\
\text { determination and } \\
\text { social-democratic } \\
\text { parameters of the } \\
\text { respondent) }\end{array}$} & 1.1. & $\begin{array}{l}\text { Your position in the survey: consumer/employee/journalist/ } \\
\text { businessman/civil servant }\end{array}$ \\
\hline & 12. & Age \\
\hline & 1.3. & Gender \\
\hline & 1.4. & Monthly income \\
\hline & 1.5 . & What city have you lived in for the last 6 months? \\
\hline & 1.6. & Have you bought anything in the supermarket in the last six months? \\
\hline $\begin{array}{l}\text { Self-determination } \\
\text { of evaluation entities } \\
\text { (brands) }\end{array}$ & 2.1. & $\begin{array}{l}\text { Choose only } 3 \text { supermarkets of the } 6 \text { proposed with which } \\
\text { you have actively interacted during the last half a year. }\end{array}$ \\
\hline \multirow{3}{*}{$\begin{array}{l}\text { Evaluation of the } \\
\text { general perception for } \\
\text { each of the selected } \\
\text { entities (brands) }\end{array}$} & 3.1 . & $\begin{array}{l}\text { Evaluate the level of trust in the brand (on a scale from } 1 \text { to } \\
5 \text {, where } 1 \text { is the minimum and } 5 \text { is the maximum rating) }\end{array}$ \\
\hline & 3.2. & Evaluate the degree of positivity of the brand reputation \\
\hline & 3.3. & Your willingness to recommend the brand \\
\hline \multirow{9}{*}{$\begin{array}{l}\text { Evaluation of the } \\
\text { criterion perception } \\
\text { for each of the } \\
\text { selected entities } \\
\text { (brands) (on a scale } \\
\text { from } 1 \text { to } 5 \text {, where } 1 \text { is } \\
\text { the minimum and } 5 \text { is } \\
\text { the maximum rating) }\end{array}$} & & $\begin{array}{l}\text { Evaluate the compliance of the brand with the following } \\
\text { criteria: }\end{array}$ \\
\hline & 4.1. & It has a transparent/public and positive history \\
\hline & 4.2 . & It provides clear and useful information/advertising \\
\hline & 4.3. & It has the clear and positive ideology and development goals \\
\hline & 4.4. & It provides a high-quality and convenient service \\
\hline & 4.5 . & It responds promptly to the concerns and allays them \\
\hline & 4.6. & $\begin{array}{l}\text { Convenient and clean supermarkets with an appropriate } \\
\text { range of goods }\end{array}$ \\
\hline & 4.7. & Competent and friendly staff \\
\hline & 4.8 . & It uses modern technologies and approaches in the work \\
\hline
\end{tabular}


Continuation Table 3

\begin{tabular}{|l|c|l|}
\hline \multicolumn{1}{|c|}{ Sets of questions } & $\begin{array}{c}\text { Number } \\
\text { of the } \\
\text { question }\end{array}$ & \\
\hline $\begin{array}{l}\text { Evaluation of the } \\
\text { importance of criteria } \\
\text { (ideal supermarket) }\end{array}$ & 5.1. & Question \\
\cline { 2 - 3 } $\begin{array}{l}\text { The maximum rating } \\
\text { is 5, the sum of all rat- } \\
\text { ings should not exceed }\end{array}$ & 5.2. & It provides clear and useful information/advertising \\
\cline { 2 - 3 } 30 points. & 5.3. & $\begin{array}{l}\text { It has the clear and positive ideology and development } \\
\text { goals }\end{array}$ \\
\cline { 2 - 3 } & 5.4. & It provides a high-quality and convenient service \\
\cline { 2 - 3 } & 5.5. & It responds promptly to the concerns and allays them \\
\cline { 2 - 3 } & 5.6. & $\begin{array}{l}\text { Convenient and clean supermarkets with an appropriate } \\
\text { range of goods }\end{array}$ \\
\cline { 2 - 3 } & 5.7. & Competent and friendly staff \\
\cline { 2 - 3 } & 5.8. & It uses modern technologies and approaches in the work \\
\hline
\end{tabular}

The survey was conducted from 12 to 28 December 2019 and it has covered 274 respondents from all stakeholder groups. The structure of the respondents distribution by stakeholder groups is given in the Table 4.

Table 4

Structure and number of respondents

\begin{tabular}{|c|c|c|c|c|c|c|}
\hline $\begin{array}{c}\text { Stakeholder } \\
\text { group }\end{array}$ & Consumer & Employee & $\begin{array}{c}\text { Civil } \\
\text { servant }\end{array}$ & Media & Businessman & Total \\
\hline $\begin{array}{c}\text { Number of online } \\
\text { respondents }\end{array}$ & 201 & 19 & 8 & 11 & 17 & 274 \\
\hline $\begin{array}{c}\text { Number of offline } \\
\text { respondents }\end{array}$ & & & 10 & 8 & & \\
\hline
\end{tabular}

According to the survey, two brands, i.e. «ECO-Market» and «Furshet», did not receive a sufficient number of responses from such stakeholder groups as «civil servants», «journalists» and «businessmen». Therefore, these brands were excluded from further analysis.

The following results were obtained from the sets of questions about general perception of each of the selected entities (brands) of evaluation:

According to the level of basic (non-categorized) brand trust (Figure 1), all 4 brands have high ratings in such stakeholder group as «consumers»: from 3.5 points for «Velyka Kyshenia» to 4.1 for NOVUS. «Silpo» and NOVUS are the leaders among such expert groups as "employees", "civil servants", "journalists", "businessmen" with average scores equal to or greater than 4 points. At the same time, ATB and "Velyka Kyshenia" have low ratings among such stakeholder groups as "employees", "journalists", "businessmen" (below 3 points), but satisfactory ratings among such stakeholder group as "civil servants" (3.2 and 4 points, respectively). It is also worth noting that the trust in all 4 brands of female consumers is slightly ( 0.2 points $)$ higher than that of male consumers. 
Trust: stakeholders and consumers

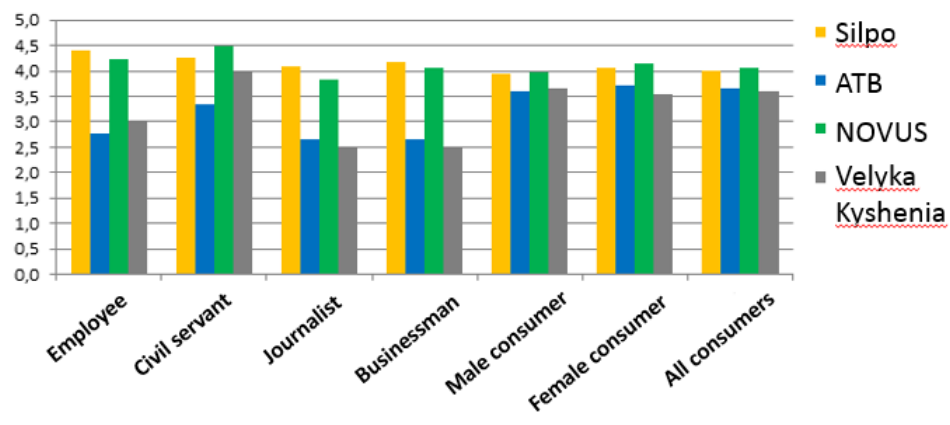

Figure 1. Level of basic (non-categorized) trust in brands

The evaluation of the basic perception of brand reputation and willingness to recommend is similar to the level of trust (Fig. 2 and Fig. 3).

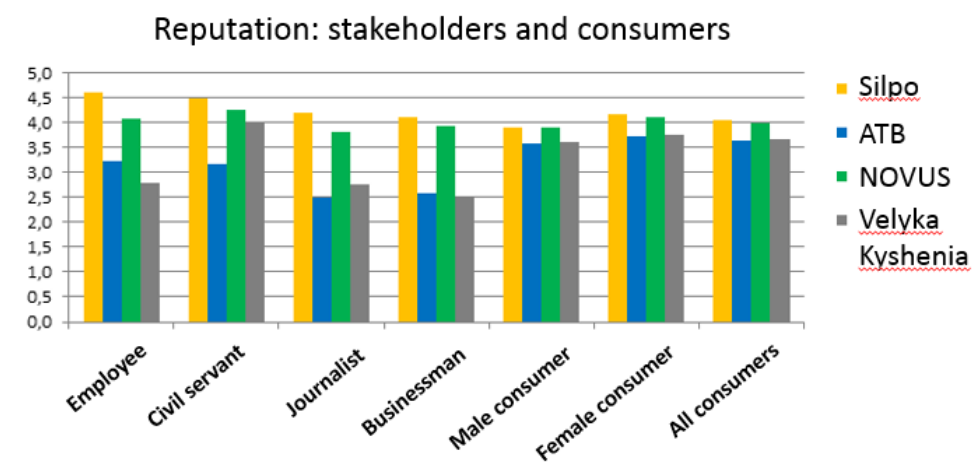

Figure 2. Basic perception of the positive reputation of brands.

Willingness to recommend: stakeholders and consumers

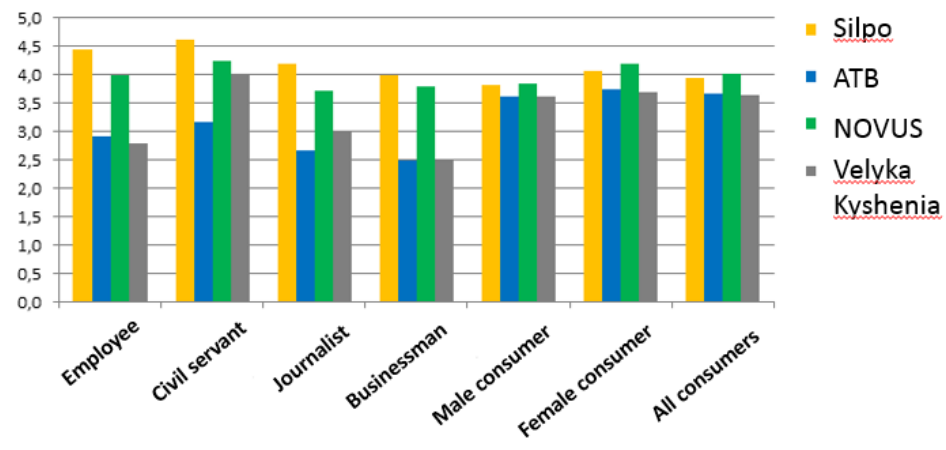

Figure 3. Basic willingness to recommend 
Subsequently, the set of questions on the formation of the reputation profile of the «ideal supermarket» (set 5 of the questionnaire) was analyzed. It is worth noting that when forming the questions of this set, the respondents were limited in the total number of points that they had to distribute between 8 attributes/criteria of the reputation profile. This was done in order to motivate respondents to a more thorough evaluation of each parameter (artificial limitation of the quantitative resource for the evaluation - the points).

According to the results of the analysis, it can be seen that the profile of the "ideal supermarket" (distribution of the attributes/profile criteria according to the importance) is characterized by a significant shift in importance (Figure 4) towards the material and technological «yesterday» and «today» component and by relatively low demand for the ideological component, material environment and technological innovations in the future.

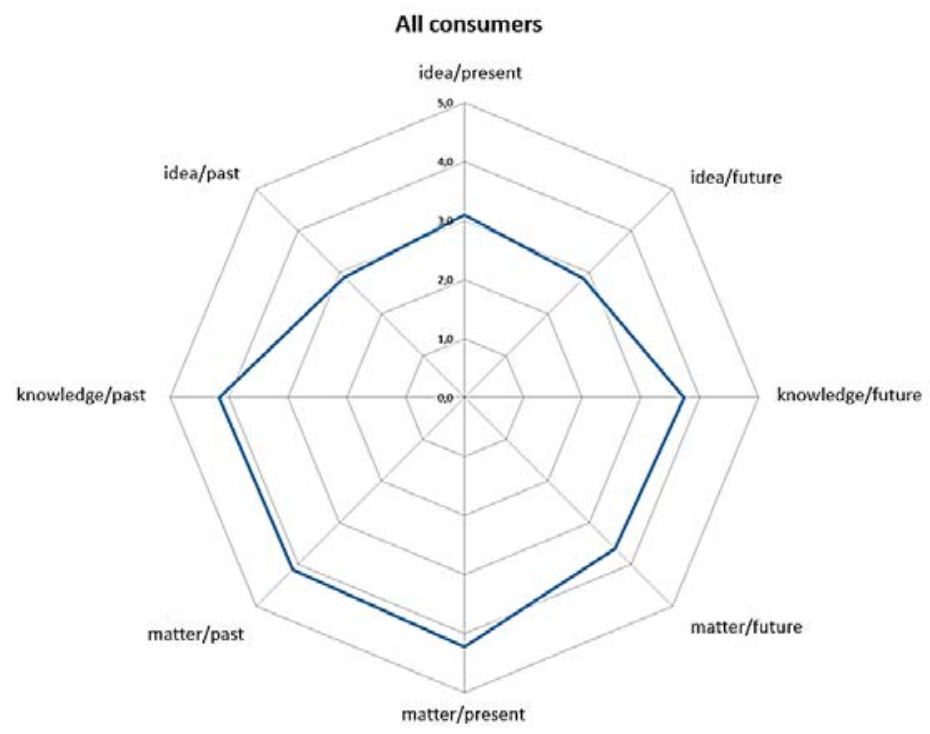

Figure 4. Reputation profile of the "ideal supermarket" from the point of view of consumers

By overlapping separate profiles (of each respondent), it can be seen (Figure 5) that there are separate extremes of ratings according to three «ideological» criteria, but the core (most respondents) is focused exactly on the material component, while the rating of the technological component are quite polar (blurred). At the same time, it is quite natural for consumers to focus on the "past" and "present" with a relatively small demand for the "future".

The next step is to analyse the portraits/profiles of the real brands (from the point of view of different consumers and stakeholder groups).

It can be observed from the consumer perception profiles of 4 brands that:

- "Silpo" and NOVUS profiles have a strong and dense core that indicates a high level and even distribution of ratings;

- ATB and "Velyka Kyshenia" profiles have much smaller core and many extremes that indicates the high polarity of ratings and uncertainty of respondents regarding the main content of the brand reputation profile;

- the core profiles of all 4 brands have a uniform shape without obvious shifts, which are inherent in the "ideal supermarket" profile. 


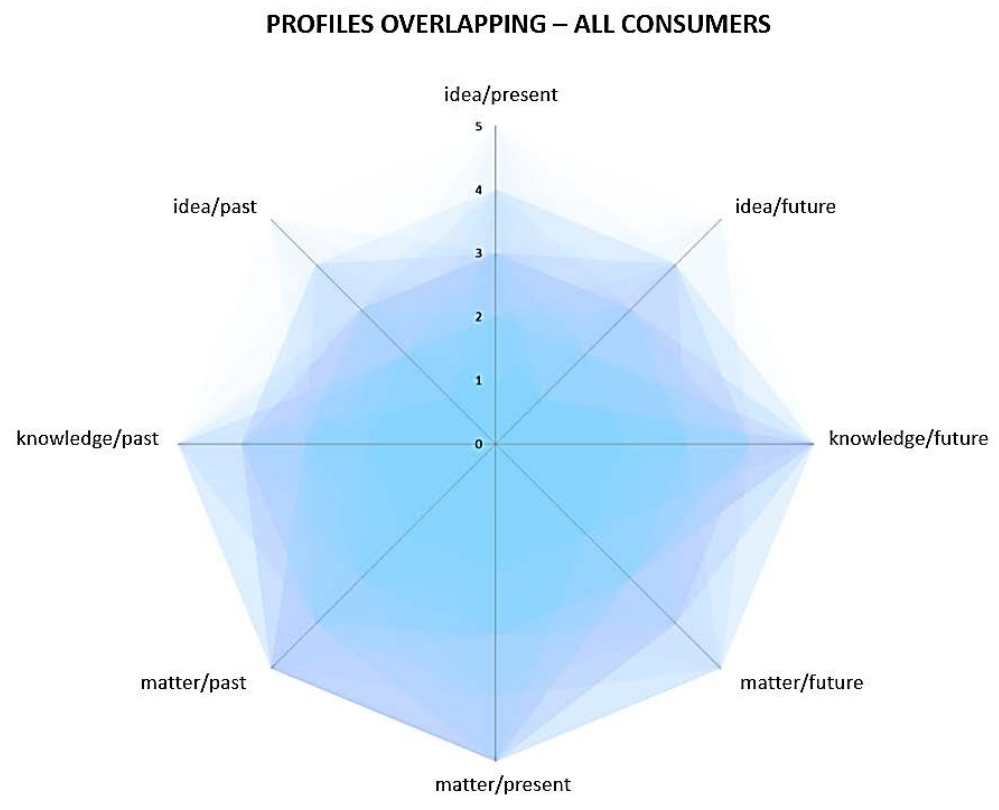

Figure 5. The overlapping of the individual respondent profiles

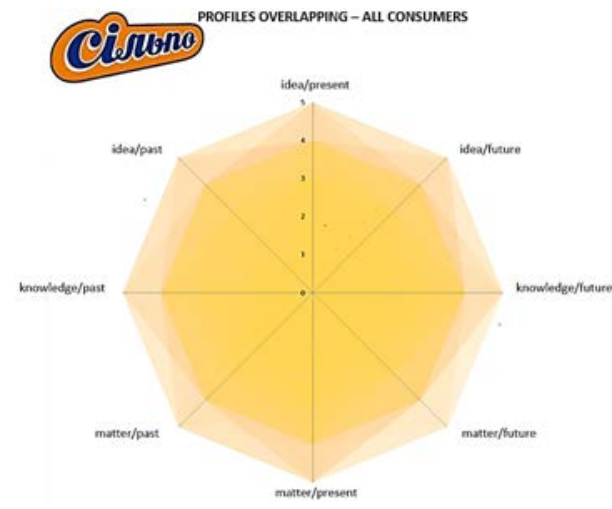

Figure 6

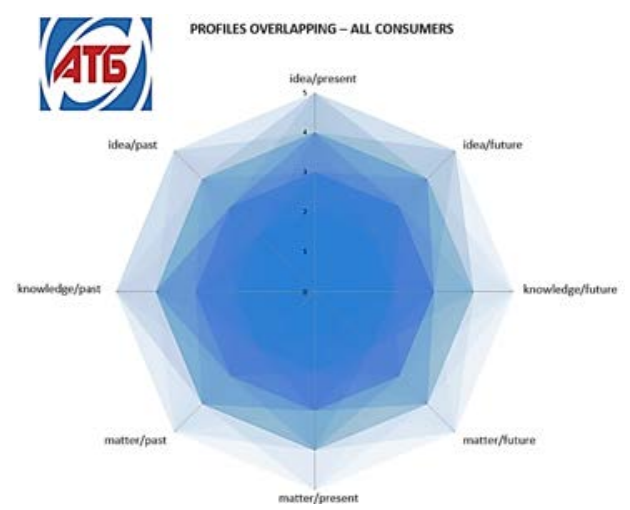

Figure 7

After that, a comparative analysis of the specific brands profile was conducted by different stakeholder groups with the perception of the «ideal supermarket» from the point of view of such stakeholder group as «consumers».

Thus, the "Silpo" brand is characterized by a high level of uniformity of the brand reputation profile perception by all audiences (Figure 10). At the same time, the employees of the sector (and of the brand in particular) give slightly higher ratings to almost all attributes/ parameters, except for "ideology today" (clarity and usefulness of advertising) than other stakeholders. It is also worth noting that on the ideological horizon, the ratings of all stakeholders 
(including the "consumers" audience) significantly exceed the expectations of "consumers" from the "ideal supermarket" and the expectations in the position of "future technology".

This profile shows a balanced brand approach to the work with all stakeholders and a high-quality combination between informational and effective (actually implemented) components of brand development.

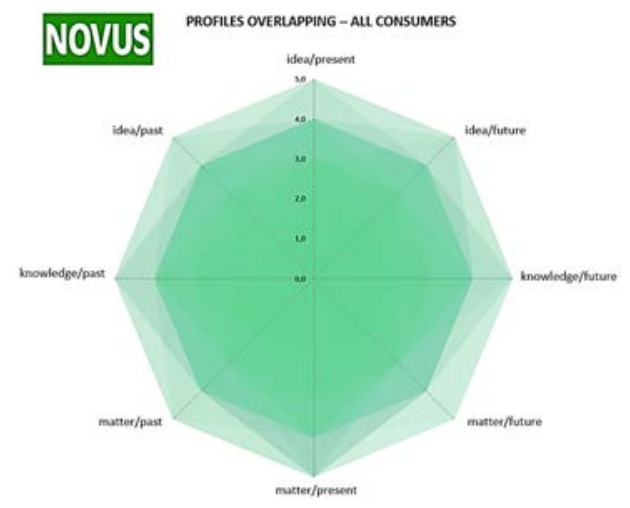

Figure 8

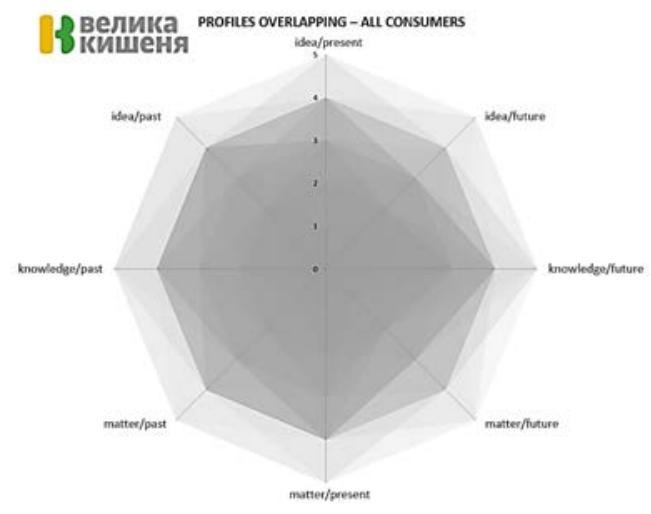

Figure 9

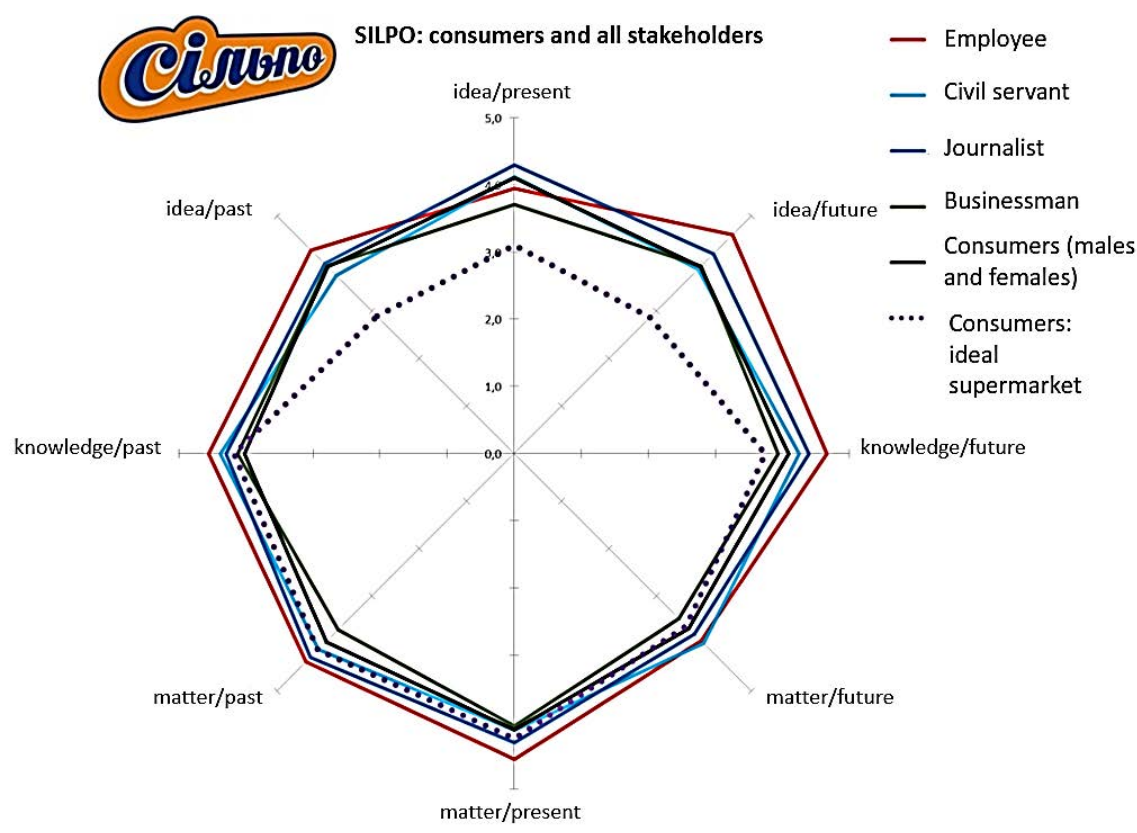

Figure 10

When analyzing the profile of the ATB brand, a different picture can be observed - the reputation profile of the ATB from the point of view of consumers has significant differences with the 
«ideal supermarket» profile. From the diagram in Figure 11 it can be seen that the ratings for all attributes from all stakeholder groups differ significantly and the ratings themselves are extremely low regarding the attributes/parameters that consumers have identified as the most important.

At the same time, most stakeholders positively evaluate the ideological horizon of ATB reputation profile, especially regarding the «clarity and usefulness of advertising» ("ideology today”) parameter.

NOVUS and "Velyka Kyshenia" brands were similarly analyzed.

The methos also makes it possible to compare the brands reputation profiles perception by different stakeholder groups.

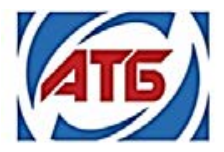

ATB: consumers and all stakeholders

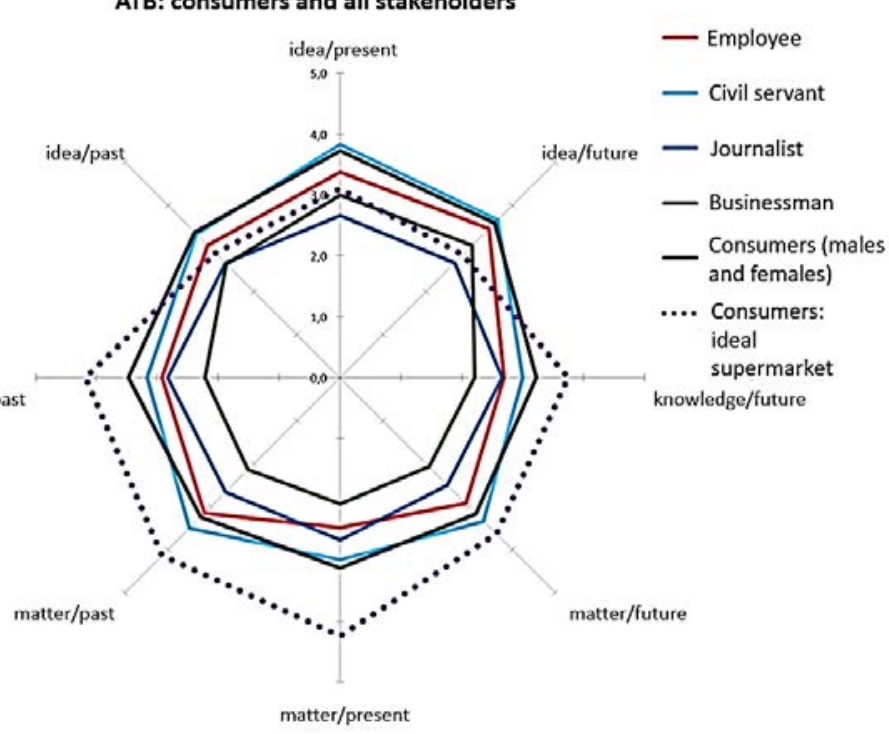

Figure 11. The ratings of reputational attributes of the ATB brand by all stakeholder groups in comparison with the attribute importance level ("ideal supermarket" profile)

\section{Conclusions}

The application of the developed method in practice has demonstrated its efficiency (the full cycle from the beginning of the survey to the end of the results analysis was 10 working days) and significantly lower cost compared to the RepTrak method. Furthermore, the results of the study have provided sufficient information to develop practical recommendations for improving the effectiveness of brand reputation management. In addition, the method has demonstrated the possibility of comparing the attitudes (ratings) of both different stakeholder groups and different socio-demographic groups of respondents. The unified approach to the attribution of the reputation profile has created opportunities both for synchronizing the results of different segments of one sector and for a comparative evaluation of the brands reputational potential from different sectors.

According to the author, the development of this method is in the direction of improving the method of calculating the integrated brand reputation indicator: the sum of the differences between the ideal and real brand for each stakeholder group is integrated into a single indicator considering the impact importance of each stakeholder group on others, and creating the objective and transparent sector and intersectoral brand reputation ratings based on it. 


\section{References}

Argenti, P., Druckenmiller, B. (2004). Reputation and the corporate brand. Corporate Reputation Review. London: Palgrave Macmillan.

Carreras, E. Alloza, A., Carreras, A. Corporate (2013). Reputation. London: LID Published Ltd.

Fombrun, C. (2007). Essentials of Corporate Communication . London: Routledge Taylor \& Francis Group.

Kashpur A. (2015). Reputacia [Reputation]. Kyiv: Logos [in Ukrainian]

Klewes J. (2009). Reputation Capital: Building and Maintaining Trust in the 21st Century. Berlin: Heidelberg: Springer-Verlag.

Murray, K. (2003). Reputation - managing the single greatest risk facing business today. Journal of Communication Managment. Melbourne: Emeraldgroup Publishing.

Sokolovskyj I. (2017). Metody izmerenyya reputacyy [Methods of reputation measurement]. Chapter 3, korporativnyj blog Reputation Capital Group [Reputation Capital Group corporate blog]. Available at: https://goo.gl/VTjiou. [in Ukraine].

The Reputation of America's 100 Most Visible Companies. (2016). Reputation Quotient Ratings. Available at: http://www.theharrispoll.com/reputation-quotient/

Vidaver-Cohen, D. (2007). Reputation Beyond the Rankings: A Conceptual Framework for Business School Research. Corporate Reputation Review. London: Palgrave Macmillan 